\title{
É A HISTÓRIA UMA FICÇÃO?
}

\author{
Maria Aparecida Barbosa* \\ Antônio Celso Mafra Júnior ${ }^{* *}$
}

Reinhart Koselleck destaca-se como um dos principais historiadores alemães do século 20. Este nasceu em 1923, em Görlitz, e estudou em Heidelberg, onde recebeu em 1965 uma cadeira como docente. Foi docente também em Bielefeld, a partir de 1972. Aposenta-se em 1988 e desde então leciona, principalmente nos Estados Unidos. Em Heidelberg, participou do grupo de estudos em História Social, juntamente com Otto Brunner e Werner Conze. Com estes pensadores, concebeu a pesquisa que viria a ser conhecida futuramente como a História dos Conceitos (Begriffsgechichte). O objetivo central deste estudo foi demonstrar a historicidade de termos constantemente utilizados e aparentemente estabelecidos nas Ciências Humanas após o Iluminismo, quando a grande maioria recebeu seus atuais significados. A História dos Conceitos é considerada o principal trabalho de Reinhart Koselleck, concluído somente nos anos de 1990, com a publicação do último volume do Dicionário de Conceitos Históricos (Geschichtlichen Grundbegriffe). O referido historiador faleceu em 2006.

A entrevista com Reinhart Koselleck, intitulada “É a História uma Ficção?”, foi originalmente publicada na revista suiça NZZ Folio (http://www.nzzfolio.ch), em março de 1995, sendo realizada por Hasso Spode. ${ }^{1}$

\footnotetext{
* Doutora em Literatura pela Universidade Federal de Santa Catarina. Professora no Departamento de Língua e Literatura Estrangeira da Universidade Federal de Santa Catarina. E-mail: mabarbos@cce.ufsc.br

** Mestrando do Programa de Pós-Graduação em Educação da UDESC. Graduando em Letras-Alemão na Universidade Federal de Santa Catarina. E-mail: antoniocelsoo@gmail.com

${ }^{1}$ Agradecemos a Markus Weininger, professor do Programa de Pós-Graduação em Estudos da Tradução, da Universidade do Federal de Santa Catarina, que realizou observações sobre o vocabulário e estilo recorrentes na historiografia alemã.
} 
Senhor Koselleck, o senhor se considera um cientista ou um autor de ficção científica a serviço da sociedade?

A ciência da História trabalha, naturalmente, também com meios ficcionais. Portanto, eu não me ofenderia se alguém me considerasse autor de ficção científica.

Afinal, a História (Historie) é uma ciência?

Cada escola de pensamento define diferentemente o que é ciência. Mas a aplicação rigorosa dos métodos "científicos" seguramente não basta para caracterizar a História (Historie). Tradicionalmente, ela se tem sempre entendido como arte; somente no século 19 esse elemento é relegado a segundo plano. Uma coisa é certa: um livro de História, escrito sem habilidade estilística, não flui.

O problema não é mais profundo que a estética? Goethe observou certa vez que a História (Geschichte) deveria ser reescrita de tempos em tempos, não com base nos fatos recém-descobertos, mas porque os "pontos de vista" mudam. Não é um dilema epistemológico, que a princípio não possa existir uma única verdade histórica?

Contudo, existe uma verdade histórica. Eu não iria tão longe para definir a História (Historie) como meramente ficcional. Há sempre um elemento de controle. Acontecimentos e estruturas podem ser verificados mediante uma metodologia comprovadamente segura. Porém, se temos somente uma verdade - como ainda supunha Ranke - ou se temos muitas verdades sobre um mesmo acontecimento, isso é outra questão. Somente se chega à verdade percebendo-a por uma perspectiva enviesada; ela necessariamente possui uma porção subjetiva.

Luís XVI morreu em 1793 sob a guilhotina: ele foi assassinado ou punido?

Sem dúvida, foi a guilhotina que separou a cabeça do corpo - aqui há somente uma verdade. Como o processo que levou à sua execução é classificado e avaliado, dependerá dos respectivos interesses e conhecimentos. Aqui me dirijo do âmbito da verdade objetiva à percepção dum ponto de vista, em outras palavras: às inúmeras verdades.

O postulado de só ter compromisso com a verdade de forma isolada já foi estabelecido na Antiguidade. O historiador Tácito, por exemplo, deveria informar com 
imparcialidade - sina ira et studio (sem ódio e sem reservas). Então seria possível dizer que a História (Historie) é a mais antiga das ciências, em geral, por ter produzido esse Ethos em primeiro lugar?

Não é possível afirmar desta maneira que a História (Historie) tenha sido a primeira ciência. A especialização era bastante precária: os gregos pensavam a História (Historie) digo também a ciência de um modo geral - como ciência essencialmente empírica. Ela incluía tanto História Natural como também Etnologia e História (Geschichte) no sentido atual, se pensarmos nos relatos de viagens de Heródoto. A Historia era uma metodologia, o caminho a um objeto que era estudado paulatinamente, com consciência. Esta limitação até o conceito de História como nós concebemos hoje já existia desde Tucídides, porém, até o século 18 prevalece seu uso como conceito mais amplo.

Teria ela ao menos como primeira ciência aprendido que o postulado da verdade nunca é inteiramente realizável, uma vez que sempre necessita operar a partir de um ponto de vista que se encontra fora do seu objeto? Essa antiga sabedoria ainda está por vir nas ciências exatas? A máxima de Einstein de que "A teoria determina o que observamos" seria então mais facilmente assinada pelos historiadores e não pelos físicos?

Sobretudo após o Princípio da Incerteza de Heisenberg, as ciências exatas se tornaram, pelo menos teoricamente, mais certas de que o caminho escolhido para definir o resultado da observação é parte do resultado de um experimento. O princípio "medir significa alterar”, relacionado ao conhecimento especulativo, leva, em última análise, à pluralidade de perspectivas conforme a conhecemos já desde o Iluminismo, na condição de hipótese do conhecimento histórico.

Novamente, o "controle" que faz da História (Geschichte) ciência e não gênero literário.

Sobre isso falei certa vez algo como do "direito de veto das fontes": não devo afirmar nada diferente do que consta na fonte. Por exemplo, se limitado a uma fonte, pergunto: César atravessou o Rubicão em 11.1.49 a.C.? E ela diz claramente sim ou claramente não, isso responde à pergunta. Além disso, todo caminho até a fonte depende da pergunta, que, por sua vez, depende da imaginação, das premissas e da perspectiva a que o pesquisador está atrelado. O que dizemos hoje sobre o passado não é o mesmo que uma figura que passa quadro a quadro, mas uma tentativa de entremear uma lacuna esgarçada por fontes incompletas. 
São incompletas, no entanto, nossas informações sobre o presente. Um “cronista ideal", uma máquina registra todos os feitos, palavras, sentimentos e pensamentos digamos, na República Democrática Alemã (RDA) no tempo da "transição" - o faria sem produzir novos sentidos sobre a "transição", mas somente dados inúteis?

Na verdade, não há conhecimento histórico sem questionamento, sem uma seleção consciente da variedade infinita, embora muitos historiadores sejam ingênuos o suficiente para trabalhar sem uma dúvida ou problema explícito! Disso pode advir uma narrativa empolgante para se ler, mas quanto a ser pesquisa, isso numa acepção bem restrita.

Existe um - crescente - núcleo de conhecimentos históricos, agrupados em torno do sentido de Goethe? Num amplo campo de novas mudanças interpretativas?

Pode-se distinguir entre percepção perspectiva e realidade, uma vez que são princípios objetivadores dos “fatos” verificáveis que resultam se compondo. Por exemplo, em que os nazistas não queimaram o Parlamento (Reichstag). Coletar tais “fatos” e assim aumentar o conhecimento é tarefa primordial do historiador. Se ele cai em um juízo contrário, precisa associar tempo, lugar e fontes técnicas dissociadas, como, por exemplo, encobrindo as disposições psicológicas e as ações visíveis. O historiador precisa fazer combinações dessas variáveis e julgar ao longo dos pressupostos não incluídos nas fontes individuais. A verdade histórica é, portanto, uma recomposição dos “fatos” e, desse modo, possui uma porção de ficcionalidade.

\section{Eu aprendi na escola que os nazistas incendiaram o Parlamento.}

A autoria solitária de Marinus van der Lubbe foi esclarecida; o exemplo mostra que houve um acúmulo de conhecimento do caso. Muitos historiadores se têm debruçado pela primeira vez sobre o mito criado em torno de 1933, de que teriam sido os nazistas mesmos ao passo que eles estavam convencidos de que teriam sido os comunistas que iniciaram o incêndio. Isso se enraizou na disposição psicológica dos partidos conflitantes. Os mitos tornaram-se fatos, criaram realidades.

\section{O mistério foi resolvido por um pirotécnico de Hannover.}

Ele também era historiador. Há uma abundância de ciências auxiliares altamente especializadas, que são necessárias para estudar a História (Historie). Da mesma forma, um 
juiz não precisa ser criminalista para julgar um crime quando coleta informações para um julgamento, porém emprega peritos.

\section{O historiador como juiz?}

Uma metáfora da descoberta do conhecimento histórico vem da justiça: inquéritos com testemunhas revelam mentiras conhecidas e desconhecidas, cada testemunha viu algo diferente e, ao final, a verdade deve vir à tona e levar ao criminoso. Isso pode mostrar que a verdade não é só uma ilusão, mas que por trás disso existe de fato uma realidade que deve ser a verdade. O que se verifica no erro judicial é o seguinte: a verdade nem sempre é esclarecida, mas em princípio pode ser esclarecida - mediante um insight.

Alguns historiadores julgam que seres humanos não foram queimados em Auschwitz. 0 que o senhor pensa da lei alemã que proíbe a difusão da chamada “Mentira de Auschwitz"?

Não estou completamente convencido de que isso faz sentido. O legislador não deveria submeter afirmações sobre fatos a juízo - por mais absurdo que isso seja, pois redundaria em processos políticos e criaria mártires. Faria surtir exatamente os efeitos que se querem evitar. A inscrição em Auschwitz sobre o número de vítimas que foram ali assassinadas deveria então ser determinada para baixo, de cinco para um milhão e meio. Quanto a isso, a crítica sobre os dados não é injustificada, mesmo que os motivos para tal crítica não sejam aceitáveis. Se se define de forma legal o que é verdade, se conduz somente água aos moleiros. Deputados e juízes não devem assumir ou ser obrigados a representar papel de historiadores. Isso cria um clima ruim, prejudicial à liberdade em uma sociedade. Em vez disso, educadores, jornalistas e historiadores deveriam exercitar cada vez mais o esclarecimento.

\section{Q̨uais "falsos juízos" fizeram os historiadores?}

Em quase todos os países, a História (Geschichte) dos processos de formação nacional produziram uma série de equívocos. 
Ernest Renan disse certa vez: “Não há nenhuma nação que não falsifique sua própria História".

... não é raro encontrar uma suave transição entre a mitologia e a historiografia, creio que decorre de uma antiga tradição oral.

No entanto, Renan afirmou também que o progresso na pesquisa histórica representa um perigo à nacionalidade. Os estudos históricos produzem ou destroem lendas?

Ambos. Ela produz uma oferta de identificação legitimada falsamente. No meio científico, as lendas florescem. Por outro lado, os historiadores destroem de fato as lendas, apontam erros, uma parte cometida com intenção político-pragmática, outra, com a crítica. Assim, ficou patente aos especialistas, no máximo ao final do século 19, que Guilherme Tell era uma figura lendária - embora ninguém quisesse ouvir isso.

O senhor apontou para a incompletude das fontes. Suponhamos que um historiador do ano 2995 pudesse recorrer ao nosso tempo a partir de algumas fitas de vídeo. Nos arquivos, ele encontraria o "Schulmädchen Report", completo. Que conclusões ele poderia tirar do sistema educacional do final do século 20?

A realidade está muitas vezes a milhas de distância da tradição. Mas sua pergunta se refere, sem dúvida, aos problemas da arqueologia pré-histórica. Não é preciso ir tão longe. Os decretos do ministro da Educação Rust documentam os projetos dos nazistas para a educação escolar do Terceiro Reich, muitos das quais não foram implementados. Sei por conta da minha experiência pessoal, como, por exemplo, na década de 1940 - mesmo na nazista Munique -, nenhuma disciplina nazista foi ministrada na minha escola, uma vez que os livros didáticos e avaliações ainda datavam da década de 1920.

Então, a possibilidade de chegar a afirmações fundamentadas, acabaria no momento em que as últimas testemunhas oculares morressem.

O testemunho dos que viveram uma época é um método autônomo que pode ser avaliado de forma positiva ou negativa. Quanto maior o apelo aos testemunhos, maior é o

\footnotetext{
${ }^{2}$ O Schulmädchen Report foi uma série de filmes produzidos na década de 1970, baseada nos livros educativos de Günther Hunold sobre sexualidade na adolescência. A partir de entrevistas com 12 garotas, com idades entre 14 e 20 anos, a série cinematográfica logo se tornou bastante polêmica na Alemanha, a despeito do apelo à pornografia (N. do T.).
} 
risco de se assumir seus preconceitos e sua ignorância, enquanto que as fontes escritas são “objetivamente” melhores e se deixam espremer como limões.

Desde que o homem é parte do conjunto de interesses do seu tempo e por não poder conhecer o futuro, ele vive em meio à "neblina" que só se dissolve quando percebida em perspectiva: assim, seriam essas as razões pelas quais não é vantajoso localizar a História? Sabemos hoje mais sobre os antigos presentes do que os nossos contemporâneos passados?

Sim e não. Isso depende do nível em que essa questão se estabelece. Hoje podemos combinar muitas fontes, que no passado não estavam disponíveis; aqui a superioridade das gerações posteriores é enorme. Mas sabemos menos sobre os sentimentos psicológicos e as experiências de vida que estão inseridas ou ocultas atrás dessas fontes. Para as gerações posteriores é muito difícil encontrar esses indícios. Aqui as testemunhas oculares podem ser um importante corretivo. Até o século 18, os relatos dos participantes diretos eram considerados fontes da mais alta importância. Desde então, o “campo do nevoeiro” foi levado mais a sério e se assumiu que as épocas mais distantes seriam mais bem pesquisadas quando livres de julgamentos. O ceticismo emergente, contrário às testemunhas oculares, estava relacionado ao advento da modernidade, juntamente com a experiência de rápidas mudanças. Mais tarde, com a Revolução Francesa, a ideia da "aceleração da História” passa a ser mais bem compreendida.

A reconstrução da vida cotidiana e das mentalidades...

... que basicamente requer uma motivação intuitiva, que se adquire com dificuldade. Isso implica a famosa "auto-responsabilidade” de Ranke, sem a qual ninguém pode se colocar de volta no tempo - como se isso fosse mesmo possível.

Pode alguém, que hoje escreve uma biografia de Barbaroxa, "entender" um assunto tão estranho? Em outras palavras: o homem é mutável ou permanece por toda parte sempre fiel ao seu "disfarce do tempo", como falou Golo Mann?

Esta pergunta é para uma antropologia histórica. Existe constância na natureza humana (a necessidade de se alimentar, a capacidade de falar e muitas outras). Essas constantes serão sempre traduzidas historicamente: cada sistema de alimentação específico, práticas sexuais e similares são moldadas culturalmente. Falemos ou não de “disfarce”, essas formas se 
modificam bastante no decorrer das épocas. Que a História tematize estruturas e processos supraindividuais, que transcendam as cabeças das pessoas, isso só sucede nos tempos modernos. Processos de longa duração existiam antes, exclusivamente entendidos como plano de salvação, como um contrato ou destino imposto por Deus.

A partir do século 19 se estabelece a "temporalidade do conhecimento": as coisas somente se esclareciam se seu desenvolvimento fosse conhecido. Isso conferiu à História enorme prestígio e importância. Nietzsche, entretanto, não gostava da História.

Não é bem assim. Em suas reflexões "Dos Usos e Desvantagens da História Para a Vida”, ele oscila entre antiquada, crítica e monumental. Mas de fato, é determinante que ele atribui à vida mais importância que à História (Historie) - assim, História como ancilla vitae (serva da vida) ao invés de magistra vitae (mestra da vida), conforme pensava Schiller. Uma inversão do que foi até agora. Então fica a pergunta: quem define a vida, a sua "serva” que é a História? Isso é muito moderno, quando você pensa sobre a instrumentalização política dos conhecimentos históricos. Nietzsche já dirigia seu olhar para a artificialidade monumental da História.

\section{De vez em quando a História se repete, não é mesmo?}

Algumas constelações e padrões de percepção podem ser congelados por séculos, apenas para serem descongelados e trazidos de volta à vida. Ainda se pensa, na França, na necessidade de uma Sérvia forte, que se interponha frente à Alemanha, juntamente com a Polônia e a Rússia. Tocqueville disse, há um século e meio atrás: é bom para a França jogar os Estados alemães uns contra os outros, enquanto os russos não são muito fortes - então a Alemanha precisará de apoio.

O que, em última instância, antecipou a constelação da Guerra Fria.

Esta constelação sobreviveria também à Guerra Fria.

Em contrapartida, nós sabemos mais sobre o tempo presente passado, porque conhecemos seu futuro.

Sim, na consumação da História, pois, no tempo presente atual, a parcela ficcional é muito maior que no retrospectivo. 
O historiador está então numa posição muito melhor do que os futuristas $e$ prognósticos? Pois ele sabe como isso começou, porque ele há muito conhece as tendências, uma vez que ele - sine ira et studio - pode ter mais distanciamento para o seu tema.

Pode-se concluir, ao menos para as corporações de ofício, que isso se verifica como vantagem. Por outro lado, um futurista de uma invejável liberdade na combinação de eventos que ainda não ocorreram tem uma maior capacidade de concepção que o historiador. Ambos necessitam da ficção, condição que os assemelha desde o princípio.

Por trás do historiador, se esconde uma habilidade profética?

Sobre isso, Schlegel estava absolutamente certo.

Recebido: Outubro/2010

Aprovado: Novembro/2010 